\title{
The effect of breastfeeding on lung function at 12 and 18 years: a prospective cohort study
}

Nilakshi T. Waidyatillake ${ }^{1}$, Julie A. Simpson², Katrina J. Allen ${ }^{3}$, Caroline J. Lodge ${ }^{1,3}$, Shyamali C. Dharmage 1,3 ${ }^{\text {, Michael J. Abramson }}{ }^{4}$, Alysha M. De Livera², Melanie C. Matheson¹, Bircan Erbas ${ }^{5}$, David J. Hill ${ }^{3}$ and Adrian J. Lowe L $^{1,3}$

Affiliations: ${ }^{1}$ Allergy and Lung Unit, Centre for Epidemiology and Biostatistics, Melbourne School of Population and Global Health, the University of Melbourne, Carlton, Australia. ${ }^{2}$ Biostatistics Unit, Centre for Epidemiology and Biostatistics, Melbourne School of Population and Global Health, the University of Melbourne, Carlton, Australia. ${ }^{3}$ Murdoch Childrens Research Institute, Melbourne, Australia. ${ }^{4}$ School of Public Health and Preventive Medicine, Monash University, Melbourne, Australia. ${ }^{5}$ School of Psychology and Public Health, La Trobe University, Melbourne, Australia.

Correspondence: Shyamali C. Dharmage, Allergy and Lung Unit, Centre for Epidemiology and Biostatistics, Melbourne School of Population and Global Health, The University of Melbourne, 207, Bouverie Street, Carlton, Vic 3052, Australia. E-mail: s.dharmagedunimelb.edu.au

ABSTRACT The objective was to assess associations between duration of total and exclusive breastfeeding and lung function up to adolescence.

A birth cohort (Melbourne Atopy Cohort Study) of 620 infants with a family history of allergic disease was recruited. Mothers were encouraged to breastfeed exclusively for 6 months. Lung function was assessed at 12 and 18 years of age. Associations between breastfeeding and lung function were investigated using multivariable linear regression and path analysis was used to assess the potential mediating factors.

Duration of breastfeeding (total and exclusive) was not associated with most assessed lung function outcomes. However, there was a trend for increased pre-bronchodilator mid-expiratory flow (MEF) at both 12 (adjusted mean difference (95\% CI) per week of breastfeeding of $10(-1-20) \mathrm{mL} \cdot \mathrm{s}^{-1}$ ) and 18 years $\left(11(-1-22) \mathrm{mL} \cdot \mathrm{s}^{-1}\right)$ ( $\mathrm{p}$-values of 0.07 and 0.08 , respectively). There was a strong indirect effect of height on these observed associations.

Duration of breastfeeding does not appear to greatly influence lung function outcomes in children with a family history of allergic diseases. Longer duration of exclusive breastfeeding may be associated with an increase in MEF, partly due to greater attained height of the child.

@ERSpublications

Duration of breastfeeding does not greatly influence lung function outcomes http://ow.ly/ZaAtE

This article has supplementary material available from erj.ersjournals.com

Received: Sept 252015 | Accepted after revision: Feb 292016 | First published online: April 132016

Support statement: N.T. Waidyatillake was supported by the Melbourne International Research Scholarship (MIRS) to undertake this work. The National Health and Medical Research Council of Australia (NHMRC) provided support for S.C. Dharmage, C.J. Lodge, M.C. Matheson and A.J. Lowe, while the Charles and Sylvia Vitrtel Medical Research Foundation supported K.J. Allen. Nestec Ltd, a subsidiary of Nestle Australia, provided the study formula and staff funding for the first 6 years of the study. The 12 years follow-up was supported by the Asthma Foundation of Victoria, while the 18 years follow-up was supported by the NHMRC Australia (APP454856).

Conflict of interest: Disclosures can be found alongside this article at erj.ersjournals.com

Copyright @ERS 2016 


\section{Introduction}

Most newborns receive breast milk as their first food [1]. There are proven benefits of breastfeeding for both mother and child, in developing and developed countries [2]. A number of studies have observed an association between prolonged breastfeeding and an increase in subsequent lung function [3-8]. However, there is variability between studies in the lung function parameters that have been shown to be enhanced by breastfeeding; with improvement in forced vital capacity (FVC) being most commonly identified [8]. Only one study failed to identify any beneficial effects of breastfeeding on lung function [9].

The mechanism to explain the improved lung function associated with breastfeeding remains unclear, but a number of theories have been proposed. It has been suggested that breastfeeding enhances lung growth and function via an immune mediated pathway [10], and breast milk has been shown to contain a host of immunologically active substances [11]. Longer duration of breastfeeding is associated with reduced weight gain in infancy [12]. Higher weight gain during infancy has been associated with early childhood wheeze [13], which is known to be associated with asthma and reduced lung function in childhood [14]. Height is also a predictor of lung function and breastfeeding has been associated with greater attained height [15]. In addition, a reduction in the incidence of respiratory tract infections has been found in exclusively breastfed infants [16]. Early life respiratory infections have been associated with both increased risk of childhood asthma [17] and poorer lung function [18].

Despite the plausibility of these associations, only three studies have attempted to identify which mediators may explain the relationship between breastfeeding and lung function, and no strong evidence of mediation has been identified $[4,5,19]$. Furthermore, there is a paucity of data to demonstrate if the beneficial effects of breastfeeding are related to the type of breastfeeding (total versus exclusive duration). To date, most of the studies of breastfeeding have been observational in nature, as it is logistically and ethically impossible to randomise individual children to breastfeeding or formula feeding. Consequently, these associations may be due to residual confounding, particularly related to socioeconomic status and early life environmental tobacco smoke exposure.

A number of factors have been proposed to modify the effect of breastfeeding on lung growth. The primary factor, although highly controversial, is whether maternal asthma may modify the beneficial effects of breastfeeding $[3,4,6]$. Of the studies to examine this issue, one showed an increase of FVC and forced expiratory volume in $1 \mathrm{~s}(\mathrm{FEV} 1)$ with increased duration of breastfeeding but only in children of mothers with asthma [4]. In contrast, another study found that, in children of mothers with asthma, breastfeeding for a total of more than 4 months was associated with reduced lung function (forced expiratory ratio (FER; defined as FEV1/FVC) and forced expiratory flow at 25-75\% of FVC (FEF25-75\%)/ FVC) [3]. The remaining study did not show any modification of the relationship between breastfeeding duration and lung function by maternal asthma or atopy [6].

To date, the findings available are inconsistent. Here we aimed to investigate the associations between breastfeeding (total and exclusive) and lung function at ages 12 and 18 years while: 1) accounting for potential confounders, 2) investigating the effect of potential mediators that might explain this relationship (height, body mass index (BMI), sensitisation and respiratory tract infections), and 3) investigating effect modification by maternal asthma.

\section{Methods}

Study design and population

The Melbourne Atopy Cohort Study (MACS) commenced as a randomised controlled trial (ACTRN12609000734268) of three infant formulas, which recruited 620 unborn babies with a family history of allergic disease between 1990 and 1994 from Melbourne, Australia [20]. Although the participants were randomly assigned to a formula group, the mothers were encouraged to breastfeed their child as long as possible. The formula was only to be used once the mother had decided cease, or partially cease, breastfeeding. As randomisation was not associated with disease outcomes [20] we have analysed MACS as a longitudinal birth cohort study [21]. The Mercy Maternity Hospital, Royal Children's Hospital and University of Melbourne Ethics Committees granted approval at different stages. Written informed consent was obtained from all mothers, and from all participants at the 18-year follow-up.

\section{Data collection}

Surveys were performed every 4 weeks from birth to 64 weeks, at 78 weeks, 2 years and then annually until the age of 7 years, and thereafter at the ages of 12 and 18 years.

Skin prick testing was performed to six allergens (cows' milk, egg white, peanut, house dust mite, rye grass and cat dander) at 6,12 and 24 months, according to standard techniques [22]. 
Spirometry was performed on each participant at 12 (pre-bronchodilator) and 18 years of age (pre- and post-bronchodilator). The American Thoracic Society (ATS) (1994) or ATS/European Respiratory Society guidelines (2005) were followed (please refer to the online supplementary material for further details) [23].

\section{Primary exposures}

Duration of exclusive and total breastfeeding was defined according to the World Health Organization (WHO) definitions [24]. Based on the questionnaire responses in the first 2 years of life, exclusive breastfeeding was defined as the period when the child was given only breast milk. Total breastfeeding was defined as the overall duration of the period when the child was given breast milk, regardless of intake of other liquids or solids.

\section{Mediators and confounders}

The following were considered as potential mediators: the number of upper respiratory tract infections during the first year of life was modelled as a continuous variable; and the presence of any lower respiratory tract infections during the first year of life and skin prick test reactivity within the first 2 years of life to any of the tested allergens $(\geqslant 3 \mathrm{~mm}$ wheal) were considered as dichotomous variables. The child's height $(\mathrm{cm})$ and BMI $\left(\mathrm{kg} \cdot \mathrm{m}^{-2}\right)$ at 12 years and 18 years were modelled as continuous variables.

Potential confounders were: maternal and paternal smoking status, maternal and paternal education, socioeconomic status of the family, eczema and cough rattle or wheeze-according to baseline data (please refer to the online supplementary material for further details). Maternal asthma and the allocated formula group were identified a priori as potential effect modifiers.

\section{Statistical analysis}

Multivariable linear regression models were used to investigate the associations between breastfeeding (measured as a continuous exposure in weeks) and lung function as continuous measures outcomes (FVC in $\mathrm{mL}, \mathrm{FEV} 1$ in $\mathrm{mL}$, mid-expiratory flow (MEF) in $\mathrm{mL} \cdot \mathrm{s}^{-1}$ and FER \%). Nonlinearity of the associations was assessed using fractional polynomials, but no evidence of nonlinearity was observed. The potential for modification of the effect of breastfeeding by maternal asthma and the randomly allocated formula group was assessed by comparing models with and without interaction terms using likelihood ratio tests (the cut-off p-value for interaction was 0.05 ). A path analysis was developed, using our previously hypothesised causal pathway [8], in order to explore the interrelated influence of the variables where possible associations were observed, and to assess if the relationship between breastfeeding and lung function was direct or indirect via our proposed mediators (described under the heading: mediators and confounders). The fit of this model was assessed using a comparative fit index (CFI) comparing the fitted model with a baseline model (CFI $\geqslant 0.95)$, a Chi-squared test comparing the fitted model with a saturated model ( $\mathrm{p}$-value $=0.3$ ), and a root mean squared error of approximation (RMSEA) that penalises the model for excessive complexity (RMSEA $\leqslant 0.05)$ [25]. Statistical analysis was performed using STATA (Version 13; Stata Corp, College Station, TX, USA), and complete case analysis was used to handle missing values.

\section{Results}

The participants of MACS were generally from well-educated families with a high socioeconomic status. $87 \%$ of mothers and $83 \%$ of fathers were born in Australia, while $59 \%$ of mothers and $61 \%$ of fathers had attended university. Of the MACS participants $51 \%$ were males. Further demographic features of the MACS cohort have been described elsewhere [26]. By the 2-year follow-up 93\% (575 subjects) were still under observation, but this had dropped to $59 \%$ and $66 \%$ of the original sample at the 12 - and 18 -year follow-ups, respectively (table 1).

Of the original 620 participants, 325 underwent spirometry at 12 years of age (median (interquartile range (IQR)) age 11.5 (10.0-12.9) years), while at the 18-year follow-up visit (median (IQR) age 17.9 (16.9-18.8) years), 409 underwent both pre- and post-bronchodilator spirometry. The mean height at the 12-year follow-up was $149 \mathrm{~cm}$ (IQR: 140-159 cm) and at 18 years was $171 \mathrm{~cm}$ (IQR: 165-179 cm).

At the 12-year follow-up, there was some evidence that longer duration of exclusive breastfeeding was associated with increased MEF (table 2). There was a $9.5 \mathrm{~mL} \cdot \mathrm{s}^{-1}(95 \% \mathrm{CI}-0.7-19.7 ; \mathrm{p}=0.07$ ) increase in the estimated mean of MEF per week of exclusive breastfeeding. To put this into context, when compared with a child who was never exclusively breastfed, a child who received 4 months $(\sim 17$ weeks $)$ of exclusive breastfeeding had, on average, $\sim 160 \mathrm{~mL} \cdot \mathrm{s}^{-1}$ greater MEF. The positive association between exclusive breastfeeding and MEF was maintained at the 18-year follow-up for the pre-bronchodilator parameters $\left(10.5 \mathrm{~mL} \cdot \mathrm{s}^{-1}\right.$ (95 \% CI $\left.\left.-1.2-22.2\right) ; \mathrm{p}=0.08\right)$, but there was no evidence of an association when post-bronchodilator outcomes were assessed. At 18 years of age the duration of exclusive breastfeeding was also associated with a very small increase in pre-bronchodilator FER $(0.1 \%$ (95\% CI $0.0-0.2)$; $\mathrm{p}=0.06)$, but 
TABLE 1 Breastfeeding practices and demographic characteristics

\begin{tabular}{|c|c|c|c|c|c|}
\hline \multirow[t]{2}{*}{ Characteristic } & \multirow[t]{2}{*}{ At baseline } & \multicolumn{2}{|c|}{12 years follow-up ${ }^{\#}$} & \multicolumn{2}{|c|}{18 years follow-up" } \\
\hline & & & p-value & & p-value \\
\hline \multicolumn{6}{|l|}{ Exclusive breastfeeding } \\
\hline$\leqslant 17$ weeks & $373(60.5)$ & 209 (57.3) & & $231(56.2)$ & \\
\hline $18-<26$ weeks & $225(36.5)$ & 149 (40.8) & & $172(41.8)$ & \\
\hline$\geqslant 27$ weeks & $16(2.6)$ & $7(1.9)$ & & $8(1.9)$ & \\
\hline Median (IQR) weeks & $14(2-20)$ & $15(2-21)$ & 0.03 & $15(2-21)$ & 0.02 \\
\hline \multicolumn{6}{|l|}{ Total breastfeeding } \\
\hline$\leqslant 17$ weeks & $154(24.8)$ & 80 (21.9) & & $88(21.4)$ & \\
\hline $18-<26$ weeks & $42(6.8)$ & $18(4.9)$ & & $24(5.8)$ & \\
\hline $27-<52$ weeks & $196(31.6)$ & $126(34.5)$ & & $132(32.1)$ & \\
\hline$\geqslant 53$ weeks & 209 (33.7) & $141(38.6)$ & & $167(40.6)$ & \\
\hline Median (IQR) weeks & $43(16-60)$ & $48(20-64)$ & $<0.01$ & $46(20-64)$ & $<0.01$ \\
\hline \multicolumn{6}{|l|}{ Sex } \\
\hline Male & $317(51.1)$ & $189(47.2)$ & 0.66 & $207(50.5)$ & 0.69 \\
\hline \multicolumn{6}{|l|}{ Maternal asthma } \\
\hline Yes & 269 (43.3) & $157(43.1)$ & 0.96 & $169(41.3)$ & 0.19 \\
\hline \multicolumn{6}{|l|}{ Maternal atopy } \\
\hline Yes & 349 (68.5) & $243(69.2)$ & 0.63 & $250(69.8)$ & 0.34 \\
\hline Maternal age (IQR) years & $31(29-34)$ & $32(29-35)$ & $<0.01$ & $32(29-34)$ & $<0.01$ \\
\hline Paternal age (IQR) years & $33(30-36)$ & $34(31-37)$ & $<0.01$ & $33(31-37)$ & 0.02 \\
\hline
\end{tabular}

Data are presented as $\mathrm{n}(\%)$, unless otherwise stated. IQR: interquartile range. Missing data: period of exclusive breastfeeding $n=4$; period of total breastfeeding $n=20$. The given $p$-values are for the group followed up compared with the group who did not attend the follow-up. ${ }^{\#}$ : $59 \%$ of the original sample;

ๆ: $66 \%$ of the original sample.

there was no increase in post-bronchodilator FER at 18 years or pre-bronchodilator FER at 12 years (table 2). Total duration of breastfeeding was not associated with any of the lung function parameters at either 12 or 18 years of age (table 2 ).

One child was exclusively breastfed for 40 weeks, which was much longer than any other child in this study. A sensitivity analysis was conducted excluding this child, and results of the association between MEF at 12 years and exclusive breastfeeding were marginally attenuated (mean difference of $10.1 \mathrm{~mL} \cdot \mathrm{s}^{-1}$

TABLE 2 Multivariable associations between breastfeeding lung function outcomes

\begin{tabular}{|c|c|c|c|c|}
\hline \multirow[t]{2}{*}{ Lung function } & \multicolumn{2}{|c|}{ Exclusive breastfeeding } & \multicolumn{2}{|c|}{ Total breastfeeding } \\
\hline & Effect per week $(95 \% \mathrm{CI})$ & p-value & Effect per week $(95 \% \mathrm{CI})$ & p-value \\
\hline \multicolumn{5}{|c|}{ Pre-bronchodilator at age 12 years ${ }^{\#}$} \\
\hline FEV1 mL & $-0.5(-4.6-3.4)$ & 0.79 & $-0.9(-2.2-0.5)$ & 0.21 \\
\hline $\mathrm{MEF} \mathrm{mL} \cdot \mathrm{s}^{-1}$ & $9.5(-0.7-19.7)$ & 0.07 & $0.4(-3.5-3.6)$ & 0.98 \\
\hline FER \% & $0.0(-0.1-0.1)$ & 0.10 & $0.0(0.0-0.0)$ & 0.89 \\
\hline FEV1 mL & $0.2(-5.4-5.8)$ & 0.95 & $-1.1(-3.0-0.8)$ & 0.24 \\
\hline $\mathrm{MEF} \mathrm{mL} \cdot \mathrm{s}^{-1}$ & $10.5(-1.2-22.2)$ & 0.08 & $-1.8(-5.8-2.2)$ & 0.37 \\
\hline FER $\%$ & $0.1(0.0-0.2)$ & 0.06 & $0.0(0.0-0.0)$ & 0.91 \\
\hline \multicolumn{5}{|c|}{ Post-bronchodilator at age 18 years $^{+}$} \\
\hline $\mathrm{FVC} \mathrm{mL}$ & $-4.0(-10.1-2.0)$ & 0.19 & $-1.4(-3.5-0.7)$ & 0.18 \\
\hline FEV1 mL & $-2.1(-7.2-3.0)$ & 0.43 & $-2.8(-6.7-1.1)$ & 0.16 \\
\hline
\end{tabular}


per week (95\% CI -0.71-20.9); p=0.067) (model 3), and breastfeeding with pre-bronchodilator MEF at 18 years was moderately attenuated $\left(6.55 \mathrm{~mL} \cdot \mathrm{s}^{-1}(95 \%\right.$ CI $-5.71-18.8)$ (model 3) when this participant was omitted.

\section{Potential mediators of the association between breastfeeding and lung function}

Both longer duration of exclusive breastfeeding and total breastfeeding were associated with a small increase in mean height at 18 years (table S4). There was also a small reduction of mean BMI associated with longer total duration of breastfeeding at 12 years.

Longer duration of total breastfeeding was associated with a reduced number of upper respiratory tract infections $(p=0.04)$. There was no evidence of an association between breastfeeding and sensitisation at 6,12 or 24 months or odds of a lower respiratory tract infection in the first 2 years of life.

\section{Direct and indirect associations}

The path analysis (figure 1) represents a theoretical causal pathway drawn to identify confounders and mediators of the relationship between exclusive breastfeeding and MEF at 18 years of age [8]. Exclusive breastfeeding was directly associated with pre-bronchodilator MEF at 18 years $\left(9 \mathrm{~mL} \cdot \mathrm{s}^{-1}\right.$ per week $(95 \% \mathrm{CI}$ $-3-20))$ and indirectly associated via height $\left(4 \mathrm{~mL} \cdot \mathrm{s}^{-1}\right.$ per week $(95 \%$ CI $\left.0.1-7.8)\right)$ in this setting.

Tables S1 and S2 show the associations with removal of height from the model (model 5), and the strength of association between exclusive breastfeeding and MEF increases slightly, particularly at 18 years (association per week increase of breastfeeding: $13.7 \mathrm{~m} \cdot \mathrm{s}^{-1}$ (95\% CI 1.6-25.5)) with a p-value of 0.03 .

\section{Effect modification}

We did not observe any interactions between duration of breastfeeding (either exclusive or total) and a history of maternal asthma (measured at baseline) with lung function outcomes at either 12 or 18 years (table S5). The associations between breastfeeding and lung function did not differ between allocated formula groups.

There was limited evidence that any of the assessed factors confounded the associations between breastfeeding and lung function. Data on birth weight were available for 226 children. In this subset of data there was no evidence that birth weight confounded the association between breastfeeding and lung function (table S6).

\section{Discussion}

In this study of children with a family history of allergic disease, we observed few associations between duration of breastfeeding and lung function outcomes at 12 and 18 years. There was some evidence of a beneficial effect of exclusive breastfeeding on pre-bronchodilator MEF at both 12 and 18 years. We did not observe any clear evidence of associations with other lung function outcomes, or with total duration of

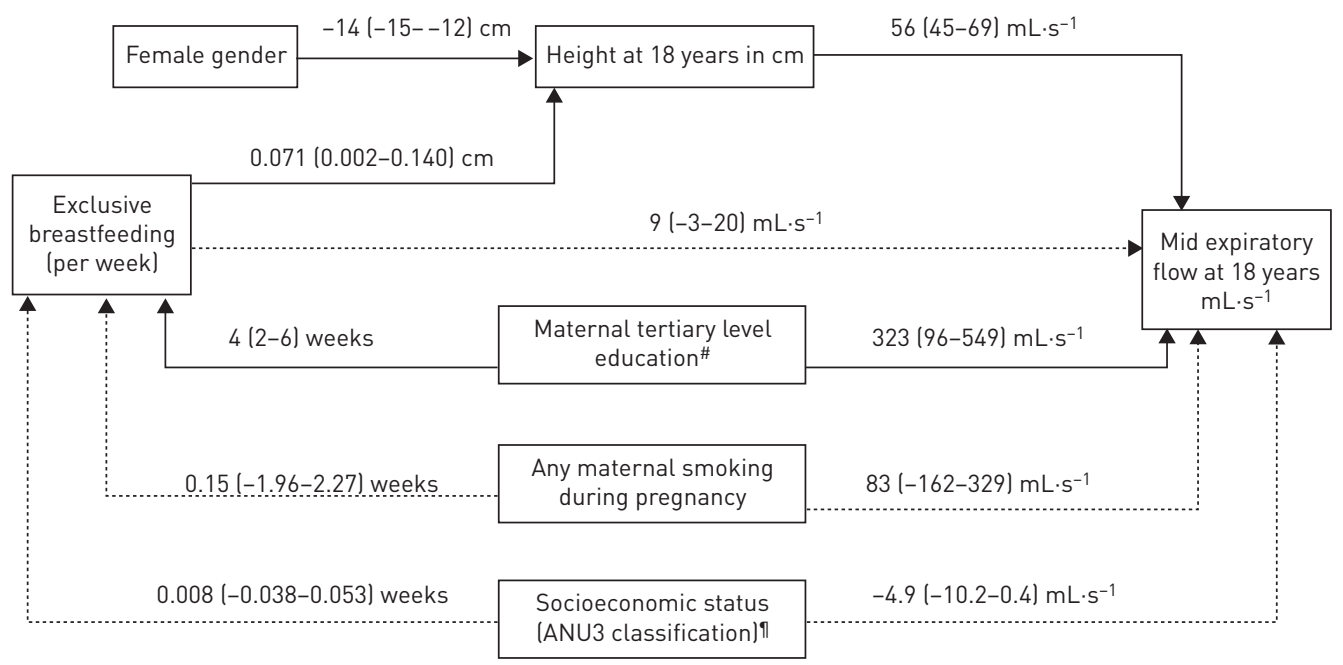

FIGURE 1 The path analysis model for factors influencing mid-expiratory flow at 18 years. Estimated mean differences $(95 \% \mathrm{CI})$ are presented. The solid arrows indicate paths with $\mathrm{p}<0.05$ and the dotted arrows indicate the hypothesised paths with $p>0.05$. \#: Maternal education has been dichotomised as completed 3 years of tertiary education versus less; ๆ: Australian National University (ANU) 3 scale (0-100) based on father's occupation at baseline. 
breastfeeding. However, a weak direct association was observed between exclusive breastfeeding and pre-bronchodilator MEF, but was strongly mediated by height at 18 years. That is, a slight increase in MEF associated with longer duration of exclusive breastfeeding appeared to be partly mediated by increased height of the child.

While a number of previous studies have examined the associations between breastfeeding and lung function outcomes, there are a number of limitations with this work. The categorisation of breastfeeding behaviour has not been consistent between studies and the most commonly measured lung function outcome parameter has been FEV1 [3-7, 9, 19, 27, 28], but the associations with this outcome have been mixed. A more consistent association between breastfeeding and increased FVC has been observed $[3,5,6]$, while MEF has been rarely assessed in previous research $[3,4]$.

Many theories have been proposed for potential pathways between breastfeeding and lung function; however, the mechanism remains unclear [29]. Possibilities include decreasing respiratory tract infections or allergic sensitisation via immune mediated pathways [30,31], a reduction in obesity or increasing attained height in childhood [5]. Only two studies have examined potential mediating effects between breastfeeding and lung function outcomes. Tennant et al. [19] examined a range of potential factors, including breastfeeding, that may influence FEV1 in much older participants (age 49-51 years), and possible mediating effects between these associations. While breastfeeding for $<4$ weeks was associated with reduced adult FEV1, no evidence of mediation by attained height or number of respiratory tract infections was identified [19]. Unfortunately, no other lung function parameters were examined in this study. Soto-RAmírez et al. [5] found breastfeeding was associated with reduced weight gain in the first year of life and greater weight gain during this period was associated with an increased FVC at 10 years. Unfortunately, we did not have birth weights or weight at 1 year available for all participants, so we could not replicate this finding. However, in this cohort we did find some evidence of both a direct association between exclusive breastfeeding and pre-bronchodilator MEF and an indirect association via height at 18 years. That is, the increase in MEF associated with longer duration of exclusive breastfeeding appeared to be partly mediated by increased height of the child. The previous findings were from population based studies whereas our results are based on a high-risk cohort, which may explain these possible differences in results.

Our finding of a possible association between breastfeeding and MEF, but not FEV1 or FEV1/FVC ratio, may indicate that MEF is a more sensitive marker of small airway obstruction than FEV1 [32, 33]. In children with asthma, MEF can be reduced with normal FEV1 [33]. It is plausible that breastfeeding has a greater impact on the development of the smaller airways, which is better identified by MEF. In support of this, of the two studies which looked at the association between breastfeeding and MEF [3, 34], one study found breastfeeding was associated with improved MEF [34], while the other found that the ratio between MEF to FVC was higher in those children with a longer duration of breastfeeding [3].

\section{Strengths and limitations}

There are number of strengths to our study. MACS is a birth cohort of children with prolonged duration of follow-up (up to 18 years). Details of dietary history were collected prospectively with 18 surveys up to the age of 24 months, including breastfeeding behaviour and complementary feeding. Therefore, there was minimal potential for recall bias. Lung function was assessed at two time-points during the follow-up and with post-bronchodilator parameters only at the 18-year follow-up. Details of mediators and effect modifiers were also assessed during the prospective data collection and we examined both direct and indirect effects using path analysis.

As with all prospective cohorts, it is possible that selective attrition may have occurred, and for this to have biased the associations observed. However, for serious bias to have occurred there would need to be a systematic difference between lung function in those who were lost and those who remained under observation, and this would need to be different based on breastfeeding duration. That is, there would need to be an interaction between loss to follow-up and breastfeeding behaviour on lung function outcomes. While possible, this does not seem likely.

As with all birth cohort studies, MACS participants were lost to follow-up over time: $40 \%$ at 12 years and $34 \%$ at 18 years of age (table 1). While these are reasonably high rates of follow-up for a study of this duration, this loss to follow-up allows some potential for selection bias. Also the study included only allergy risk children, so the results cannot be directly applied to general populations. All mothers were encouraged to establish breastfeeding according to breastfeeding guidelines. Almost all children established breastfeeding after birth. As very few children did not receive any breast milk, it was not possible to examine the effect of any versus no breastfeeding. Furthermore participants who persisted in the study during this long follow-up may have health seeking behaviours that might impact on the results. 
In conclusion, among children with a family history of allergic disease, duration of total and exclusive breastfeeding was not related to FVC and FEV1 at age 12 and 18 years. There was weak evidence that longer duration of exclusive breastfeeding was associated with improved MEF and that this association may be mediated by increased height, but this finding needs to be replicated. A reduced risk of respiratory tract infections or adiposity associated with breastfeeding do not appear to fully explain this association. Breastfeeding should continue to be promoted, particularly exclusive breastfeeding, as it has multiple health benefits.

\section{Acknowledgements}

We thank Christine Axelrad (Murdoch Childrens Research Institute, Melbourne, Australia), Catherine Bennett (Deakin University, Melbourne, Australia), Cliff Hosking (John Hunter Children's Hospital, Newcastle, Australia) and John Thorburn (Mercy Maternity Hospital, Melbourne, Australia) for the contribution in the early phase of the study. We also thank the Melbourne Atopy Cohort Study children and their families for their ongoing support in this study.

\section{References}

1 Lugonja N, Spasic SD, Laugier O, et al. Differences in direct pharmacologic effects and antioxidative properties of mature breast milk and infant formulas. Nutrition 2013; 29: 431-435.

2 Ip S, Chung M, Raman G, et al. Breastfeeding and maternal and infant health outcomes in developed countries. Evid Rep Technol Assess (Full Rep) 2007; 1-186.

3 Guilbert TW, Stern DA, Morgan WJ, et al. Effect of breastfeeding on lung function in childhood and modulation by maternal asthma and atopy. Am J Respir Crit Care Med 2007; 176: 843-848.

4 Dogaru CM, Strippoli MP, Spycher BD, et al. Breastfeeding and lung function at school age: does maternal asthma modify the effect? Am J Respir Crit Care Med 2012; 185: 874-880.

5 Soto-Ramírez N, Alexander M, Karmaus W, et al. Breastfeeding is associated with increased lung function at 18 years of age: a cohort study. Eur Respir J 2012; 39: 985-991.

6 Ogbuanu IU, Karmaus W, Arshad SH, et al. Effect of breastfeeding duration on lung function at age 10 years: a prospective birth cohort study. Thorax 2009; 64: 62-66.

7 Kull I, Melen E, Alm J, et al. Breast-feeding in relation to asthma, lung function, and sensitization in young schoolchildren. J Allergy Clin Immunol 2010; 125: 1013-1019.

8 Waidyatillake NT, Allen KJ, Lodge CJ, et al. The impact of breastfeeding on lung development and function: a systematic review. Expert Rev Clin Immunol 2013; 9: 1253-1265.

9 Shaukat A, Freudenheim JL, Grant BJ, et al. Is being breastfed as an infant associated with adult pulmonary function? J Am Coll Nutr 2005; 24: 327-333.

10 Ballard O, Morrow AL. Human milk composition: nutrients and bioactive factors. Pediatr Clin North Am 2013; 60: 49-74.

11 Goldman AS, Garza C, Nichols BL, et al. Immunologic factors in human milk during the first year of lactation. J Pediatr 1982; 100: 563-567.

12 Gubbels JS, Thijs C, Stafleu A, et al. Association of breast-feeding and feeding on demand with child weight status up to 4 years. Int J Pediatr Obes 2011; 6: e515-e522.

13 Turner S, Zhang G, Young S, et al. Associations between postnatal weight gain, change in postnatal pulmonary function, formula feeding and early asthma. Thorax 2008; 63: 234-239.

14 Castro-Rodríguez JA, Holberg CJ, Morgan WJ, et al. Increased incidence of asthmalike symptoms in girls who become overweight or obese during the school years. Am J Respir Crit Care Med 2001; 163: 1344-1349.

15 Budhiraja S, Singh D, Pooni PA, et al. Pulmonary functions in normal school children in the age group of 6-15 years in north India. Iran J Pediatr 2010; 20: 82-90.

16 Li R, Magadia J, Fein SB, et al. Risk of bottle-feeding for rapid weight gain during the first year of life. Arch Pediatr Adolesc Med 2012; 166: 431-436.

17 Escribano J, Luque V, Ferre N, et al. Effect of protein intake and weight gain velocity on body fat mass at 6 months of age: the EU Childhood Obesity Programme. Int J Obes 2012; 36: 548-553.

18 Oddy WH, de Klerk NH, Sly PD, et al. The effects of respiratory infections, atopy, and breastfeeding on childhood asthma. Eur Respir J 2002; 19: 899-905.

19 Tennant PW, Gibson GJ, Pearce MS. Lifecourse predictors of adult respiratory function: results from the Newcastle Thousand Families Study. Thorax 2008; 63: 823-830.

20 Lowe AJ, Hosking CS, Bennett CM, et al. Effect of a partially hydrolyzed whey infant formula at weaning on risk of allergic disease in high-risk children: a randomized controlled trial. J Allergy Clin Immunol 2011; 128: 360-365.

21 Lodge CJ, Zaloumis S, Lowe AJ, et al. Early-life risk factors for childhood wheeze phenotypes in a high-risk birth cohort. J Pediatr 2014; 164: 289-294.

22 Lowe AJ, Hosking CS, Bennett CM, et al. Skin prick test can identify eczematous infants at risk of asthma and allergic rhinitis. Clin Exp Allergy 2007; 37: 1624-1631.

23 Lodge CJ, Lowe AJ, Allen KJ, et al. Childhood wheeze phenotypes show less than expected growth in FEV1 across adolescence. Am J Respir Crit Care Med 2014; 189: 1351-1358.

24 World Health Organization. The World Health Organization's infant feeding recommendation. www.who.int/ nutrition/topics/infantfeeding_recommendation/en/ Date last accessed: May 17, 2013.

25 Acock AC. Discovering Structural Equation Modeling Using Stata. College Station, Stata Press, 2013.

26 Lowe AJ, Carlin JB, Bennett CM, et al. Atopic disease and breast-feeding - cause or consequence? J Allergy Clin Immunol 2006; 117: 682-687.

27 Nagel G, Büchele G, Weinmayr G, et al. Effect of breastfeeding on asthma, lung function and bronchial hyperreactivity in ISAAC Phase II. Eur Respir J 2009; 33: 993-1002.

28 Lee N, Banerjee I, Mukherjee D, et al. Letters to the Editor. J Hum Lact 2005; 21: 120-123.

29 Penttila IA. Milk-derived transforming growth factor- $\beta$ and the infant immune response. J Pediatr 2010; 156: Suppl., S21-S25. 
30 Cunningham AS, Jelliffe DB, Jelliffe EF. Breast-feeding and health in the 1980s: a global epidemiologic review. J Pediatr 1991; 118: 659-666.

31 Cushing AH, Samet JM, Lambert WE, et al. Breastfeeding reduces risk of respiratory illness in infants. Am J Epidemiol 1998; 147: 863-870.

32 Rao DR, Gaffin JM, Baxi SN, et al. The utility of forced expiratory flow between $25 \%$ and $75 \%$ of vital capacity in predicting childhood asthma morbidity and severity. J Asthma 2012; 49: 586-592.

33 Sposato B, Scalese M, Migliorini MG, et al. Small airway impairment and bronchial hyperresponsiveness in asthma onset. Allergy Asthma Immunol Res 2014; 6: 242-251.

34 Dogaru CM, Strippoli M-PF, Spycher BD, et al. Breastfeeding and lung function at school age: does maternal asthma modify the effect? Am J Respir Crit Care Med 2012; 185: 874-880. 